Oxygen therapy in COPD

\section{Oxygen: the good, the bad, and the necessary...}

\section{T Troosters}

\section{The use of oxygen therapy in COPD needs more careful study}

$\mathrm{L}$ ong term oxygen therapy (LTOT) is one of the few treatments which has - significant survival benefits in patients with severe hypoxaemia. It may modify disease progression, as indicated by a slower progression of hypoxia induced pulmonary hypertension, ${ }^{1-4}$ and the acute reduction in pulmonary hypertension to oxygen administration has been suggested as predictive for the survival benefit in individual patients. Reduced pulmonary vascular resistance and hence the reduced load on the right heart is probably the most important working mechanism of LTOT. In less severe hypoxaemic patients the benefits of LTOT on survival are less clear. ${ }^{5}$ Other benefits of oxygen administration are generally accepted. Reduced ventilation, especially during exercise, helps to avoid dynamic hyperinflation and hence reduces symptoms and increases exercise tolerance in the majority of patients with chronic obstructive pulmonary disease (COPD), even in patients with mild hypoxaemia. ${ }^{6}$ There is also some evidence to support the suggestion that LTOT may improve cognitive function in hypoxaemic COPD patients ${ }^{7}$ and may improve health related quality of life. ${ }^{8}$

LTOT is therefore a recognised treatment in hypoxaemic patients 9 and has been reimbursed in most healthcare systems. During exercise training oxygen supplements are administered to enhance training intensity ${ }^{10}$ or relieve symptoms.

Despite the proven benefits of oxygen therapy, researchers should remain critical towards interventions. ${ }^{11}$ In this issue of Thorax Carpagnano et $a l^{12}$ present interesting data that potentially invite us to refine our view on the benefits of oxygen therapy in COPD. The authors investigated the effects of acute administration of hyperoxia $\left(\mathrm{FIO}_{2}\right.$ $28 \%$ ) on markers of oxidative stress and inflammation in exhaled breath condensate. They found that exposure to increased inspiratory oxygen fractions for 1 hour exacerbated 8-isoprostane and interleukin (IL)-6 concentrations (already raised breathing ambient air) compared with control subjects.
Intriguingly, the effect of oxygen breathing was comparable between healthy subjects (IL-6 +68\%, 8 -isoprostane $+79 \%$ ) and patients with COPD (IL-6 $+31 \%$, 8-isoprostane $+49 \%$ ). In other words, the effects of oxygen breathing were not restricted to COPD. In addition, the increases in both markers were significantly interrelated.

Although the data by Carpagnano et al are tantalizing for researchers in this field, the clinical relevance of the findings is not yet clear. Firstly, the use of markers in exhaled air is not an easy technique and it is difficult to reproduce findings in other laboratories. ${ }^{13} 14$ Secondly, the magnitude of the increase in IL-6 and 8-isoprostane is difficult to put into context. The same research group has already shown that, in smokers, IL-6 levels in exhaled air were more than double $(+115 \%)$ those observed in non-smokers. In heavy smokers IL- 6 was $+184 \%$ above control levels. The changes observed with oxygen breathing $(+68 \%$ in healthy subjects and $+31 \%$ in COPD patients) are therefore relatively subtle-and the clinical relevance might also be. ${ }^{15}$ Thirdly, the authors studied only one time point (after 1 hour of oxygen breathing), which makes it difficult to extrapolate to LTOT. It would be useful to know whether the observed effects are transient or whether the increased oxidative stress and inflammatory markers remain. Lastly, oxygen administration may exert different effects in the lungs from the "periphery". COPD is more and more recognised as a systemic disease ${ }^{16}$ or a disease with systemic consequences. Oxygen administration may protect against the systemic consequences of COPD. For instance, oxygen administration has been shown to protect against systemic oxidative stress during a bout of exercise ${ }^{17}$ and, interestingly, Carpagnano et $a l^{18}$ have confirmed elsewhere that temporary hypoxia induced, for instance, by sleep apnoea leads to an increase in the markers of oxidative stress. These are normalised when overall oxygenation is improved with continuous positive airway pressure (CPAP). In patients with severe gas exchange disturbances, hyperoxia in the alveolar spaces may be needed to guarantee relative normoxia in the periphery of these patients. It is generally recognised that tissue hypoxia contributes to weight loss through the activation of the NF- $\kappa B$ pathway, which activates an inflammatory cascade releasing IL- 6 and tumour necrosis factor (TNF)- $\alpha^{19}$ leading to tissue wasting. Weight loss-especially the loss of lean tissue-is in itself is a negative prognostic factor and should be avoided in COPD. ${ }^{20}$ Since the same NF$\kappa \mathrm{B}$ pathway has been suggested to play a role in hyperoxia induced oxidative stress, it is not clear at present whether increased $\mathrm{FIO}_{2}$ is good or bad.

Hyperoxia up to concentrations of $80 \% \mathrm{FiO}_{2}$ did not seem to lead to weight loss in rats. ${ }^{21}$ In the MRC LTOT trial ${ }^{1}$ patients surviving in the LTOT arm did not tend to lose weight, nor did their lung function deteriorate more rapidly than in the control arm. Hence, somewhat increased $\mathrm{FIO}_{2}$ values used in LTOT or during exercise to improve tissue oxygenation are therefore probably clinically superior to normoxia in the lungs, leading to relative tissue hypoxia. Evidence of "harm" induced by relatively modest $\mathrm{FIO}_{2}$ is absent. Oxygen therapy therefore remains recommended-if not necessary-in patients at risk of tissue hypoxia.

In summary, the study reported by Carpagnano et al may shed new light on the effect of clinical doses of pulsed oxygen therapy on patients with COPD, and could be interpreted as a potential sign to be cautious in using oxygen therapy in these patients as it may exacerbate rather than alleviate the bronchial inflammation by inducing hyperoxia induced oxidative stress.

This study invites further research rather than a change in clinical routine.

Thorax 2004;59:1005-1006. doi: $10.1136 /$ thx.2004.031617

Correspondence to: T Troosters, PhD, Respiratory Rehabilitation and Respiratory Division, UZ Gasthuisberg, Herestraat 49, B-3000 Leuven, Belgium; Thierry.Troosters@ med.kuleuven.ac.be

Thierry Troosters is a postdoctoral fellow of the 'Fonds voor Wetenschappeliik OnderzoekVlaanderen'. He is affiliated with the Department of Rehabilitation Sciences, Ku-Leuven, B-3000 Leuven, Belgium.

\section{REFERENCES}

1 Medical Research Council Working Party. Long term domiciliary oxygen therapy in chronic hypoxic cor pulmonale complicating chronic bronchitis and emphysema. Lancet 1981;1:681-6.

2 Continuous or nocturnal oxygen therapy in hypoxemic chronic obstructive lung disease: a clinical trial. Nocturnal Oxygen Therapy Trial Group. Ann Intern Med 1980;93:391-8. 
3 Weitzenblum EA, Sautegeau $M$, Ehrhart $M$, et al. Long-term oxygen therapy can reverse the progression of pulmonary hypertension in patients with chronic obstructive pulmonary disease. Am Rev Respir Dis 1985;131:493-8.

4 Zielinski JM, Tobiasz I, Hawrylkiewicz P, et al. Effects of long-term oxygen therapy on pulmonary hemodynamics in COPD patients: a 6 -year prospective study. Chest 1998;113:65-70.

5 Gorecka DK, Gorzelak P, Sliwinski M, et al. Effect of long-term oxygen therapy on survival in patients with chronic obstructive pulmonary disease with moderate hypoxaemia. Thorax 1997; 52:674-9.

6 Somfay AJ, Porszasz S, Lee M, et al. Doseresponse effect of oxygen on hyperinflation and exercise endurance in nonhypoxaemic COPD patients. Eur Respir J 2001;18:77-84.

7 Heaton RK, Grant I, McSweeny AJ, et al. Psychologic effects of continuous and nocturnal oxygen therapy in hypoxemic chronic obstructive pulmonary disease. Arch Intern Med 1983; 143:1941-7.

8 Eaton TC, Lewis $P$, Young $Y$, et al. Long-term oxygen therapy improves health-related quality of life. Respir Med 2004;98:285-93.
9 National Institute for Clinical Excellence (NICE). Chronic obstructive pulmonary disease: national clinical guideline for the management of COPD in adults in primary and secondary care. Thorax 2004;59(Suppl 1).

10 Emtner MJ, Porszasz M, Burns A, et al. Benefits of supplemental oxygen in rehabilitative exercise training in non-hypoxemic COPD patients. Eur Respir J 2002;20:235s.

11 Calverley PM. Supplementary oxygen therapy in COPD: is it really useful? Thorax 2000;55:537-8.

12 Carpagnano GE, Kharitonov SA, FoschinoBarbaro MP, ef al. Supplementary oxygen in healthy subjects and those with COPD increases oxidative stress and airway inflammation. Thorax 2004:59:1016-19.

13 Van Hoydonck PG, Wuyts WA, Vanaudenaerde BM, et al. Quantitative analysis of 8-isoprostane and hydrogen peroxide in exhaled breath condensate. Eur Respir J 2004;23:189-92

14 Rahman I. Reproducibility of oxidative stress biomarkers in breath condensate: are they reliable? Eur Respir J 2004;23:183-4.

15 Carpagnano GE, Kharitonov SA, FoschinoBarbaro MP, et al. Increased inflammatory

\section{Non-invasive ventilation in acute exacerbations of COPD: what happens after hospital discharge?}

M W Elliott

\section{The role of domiciliary NIV in patients with COPD}

$\mathrm{N}$ ow that non-invasive ventilation (NIV) is well established in clinical practice, particularly for chronic obstructive pulmonary disease (COPD), ${ }^{12}$ it is likely that more patients will survive an acute exacerbation, especially in countries such as the UK where comparatively few patients with COPD are ventilated invasively. However, it is possible that some patients are now just being saved for a future life of poor quality at home, punctuated by recurrent admissions to hospital because their respiratory reserve is so marginal that even trivial exacerbations are sufficient to provoke life threatening ventilatory failure.

Before NIV was widely available, Connors et $\mathrm{al}^{3}$ showed that hypercapnia during an admission with an acute exacerbation of COPD was a poor prognostic indicator. In a prospective study of a cohort of 1016 patients who were admitted with an exacerbation of COPD and $\mathrm{a}^{\mathrm{PaCO}_{2}}$ of $50 \mathrm{~mm} \mathrm{Hg}(6.6 \mathrm{kPa})$ or more, they found that $11 \%$ of the patients died during the index hospital stay. The 60 day (20\%), 180 day (33\%),
1 year (43\%), and 2 year (49\%) mortality rates were all high; 446 patients $(44 \%)$ were readmitted 754 times in the following 6 months. At 6 months only $26 \%$ of the cohort were both alive and able to report a "good", "very good", or "excellent" quality of life. Survival time was independently related to severity of illness, body mass index (BMI), age, prior functional status, $\mathrm{PaO}_{2} / \mathrm{FiO}_{2}$, congestive heart failure, serum albumin, and the presence of cor pulmonale. Given that current recommendations state that patients with an acute respiratory acidosis $(\mathrm{pH}<7.35)$ after initial treatment and a $\mathrm{PaCO}_{2}$ above $6 \mathrm{kPa}$ should be offered NIV, ${ }^{4}$ all patients who have received NIV acutely fall into this poor prognostic group.

\section{LONG TERM OUTCOME FOLLOWING NIV IN HOSPITAL}

A number of studies have looked at the longer term follow up after an admission requiring NIV. Overall the prognosis is poor, but patients receiving NIV acutely appear to fare better than those who require endotracheal intubation markers in the exhaled breath condensate of cigarette smokers. Eur Respir $J$ 2003;21:589-93.

16 Reid MB. COPD as a muscle disease. Am J Respir Crit Care Med 2001; 164:1101-5.

17 Vina JE, Servera M, Asensi J, et al. Exercise causes blood glutathione oxidation in chronic obstructive pulmonary disease: prevention by $\mathrm{O}_{2}$ therapy. J Appl Physiol 1996;81:2198-202.

18 Carpagnano GE, Kharitonov SA, Resta O, et al. Increased 8-isoprostane and interleukin- 6 in breath condensate of obstructive sleep apnea patients. Chest 2002;122:1162-7.

19 Takabatake NH, Nakamura S, Abe S, et al. The relationship between chronic hypoxemia and activation of the tumor necrosis factor-alpha system in patients with chronic obstructive pulmonary disease. Am J Respir Crit Care Med 2000;161:1179-84.

20 Schols AM, Slangen J, Volovics L, et al. Weight loss is a reversible factor in the prognosis of chronic obstructive pulmonary disease. Am J Respir Crit Care Med 1998;157:1791-7.

21 Coursin DB, Cihla HP, Will JA, et al. Adaptation to chronic hyperoxia. Biochemical effects and the response to subsequent lethal hyperoxia. Am Rev Respir Dis 1987;135:1002-6.
(ETI) and mechanical ventilation (MV). In their randomised controlled trial comparing NIV with immediate ETI and MV, Conti et al showed that, in those who could be managed successfully with NIV, there was an advantage both in the short term and also in the year after hospital discharge. There were fewer admissions to hospital and ICU, and fewer patients needed de novo long term oxygen therapy (LTOT). There was also a trend towards improved survival ( $74 \% v 54 \%, \mathrm{p}=0.43)$. This confirms the findings of two previous studies comparing NIV patients with historical controls who had been invasively ventilated. ${ }^{67}$ Imperfect matching is one possible explanation in these studies, ${ }^{8}$ but patients who are intubated and mechanically ventilated may lose a considerable amount of muscle bulk rendering them susceptible to further episodes of ventilatory failure. ${ }^{9}{ }^{10}$ Longer term follow up from the study by Plant et $a l^{11}$ failed to show any statistically significant benefit from NIV compared with conventional therapy. It may be significant that few patients in either group were intubated and ventilated and this is an important difference when compared with the studies mentioned above. The study showed a median survival of 13 and 16 months in the conventional and NIV groups, respectively. In a retrospective study of 120 patients who had received NIV acutely, Scala et $a l^{12}$ found a 6 month mortality rate of $35 \%$; this was greater in those with chronic co-morbidities (54\%) than in those without $(30 \%)$, and was greater in those with low activities of daily living scores.

In this issue of Thorax Chu et al ${ }^{13}$ report their experience on post-discharge 
outcomes (need for further hospitalisation, recurrent respiratory failure requiring ventilatory support, and death) and the risk factors associated with them in 110 patients ventilated non-invasively for an acute exacerbation of COPD. During the year following discharge $79.9 \%$ were readmitted, $63.3 \%$ had another life threatening event, and $49.1 \%$ died. Survivors spent a median of $12 \%$ of days in hospital in the subsequent year. The number of days in hospital in the previous year and a low Katz score (indicating difficulty with activities of everyday living) predicted early readmission; home oxygen use, APACHE II score, and a lower BMI predicted early recurrent acute hypercapnic respiratory failure or death; and the MRC dyspnoea score predicted early death.

\section{USE OF DOMICILIARY NIV}

It is clear that patients who have received NIV for an acute exacerbation of COPD are a group at high risk for subsequent hospitalisation and death; those at the most severe end of the spectrum are not surprisingly those at most risk. NIV at home for these patients might improve the long term outcome. Is there any evidence to support this? In a 1 year controlled trial Casanova et al ${ }^{14}$ randomised 52 patients with severe stable COPD to either NIV plus "standard care" or to standard care alone. One year survival was similar in both groups $(78 \%)$ as was the number of acute exacerbations. The number of hospital admissions was less at 3 months in the NIV group (5\% v 15\%, $\mathrm{p}<0.05$ ), but this difference was not seen at 6 months (18\% $\vee 19 \%$, respectively). There was either no or little difference between the groups in dyspnoea scales, gas exchange, haematocrit, pulmonary function, cardiac function, and neuropsychological performance. However, the number of patients was too small to avoid a type II error. Clini et al ${ }^{15}$ conducted a prospective randomised controlled trial of 90 patients randomised to continuing LTOT alone or LTOT with the addition of NIV. There were small improvements in the NIV group in resting $\mathrm{PaCO}_{2}$ and dyspnoea and health related quality of life. There was no improvement in survival or hospital stay, although there was a trend towards less time in hospital in the NIV group compared with an increase in the LTOT group when compared with the period before the study. ICU stay was reduced in both groups, but more in the NIV group than in the LTOT group.

The suggestion of reduced hospitalisation rates (neither study was powered to address this end point) in both these studies is an interesting observation. The level of ventilatory support in both was modest and, while it has been suggested that this may not have been sufficient to control sleep related hypoventilation, ${ }^{16}$ ventilator settings similar to those used in these studies offload the respiratory muscles ${ }^{17}$ and reduce the sensation of dyspnoea ${ }^{18}{ }^{19}$ associated with an acute exacerbation. It is possible that NIV reduced the impact of exacerbations upon the patient and this may have contributed to the trend towards reduced hospitalisation. In a small group of highly selected patients admitted to hospital recurrently with exacerbations of COPD requiring NIV, Tuggey $e t a l^{20}$ showed a reduction in the need for hospital and ICU admission in the year following the introduction of home NIV compared with the year before. This was associated with a reduction in costs even when that of the ventilator, masks, etc was taken into account. However, this study was uncontrolled and the quality of life of the patients was not measured. A placebo effect of NIV cannot be discounted and has been seen with sham $\mathrm{CPAP}^{21}$ and sham NIV. ${ }^{22}$ The placebo effect of a "breathing machine" to a patient who is very short of breath should not be underestimated.

\section{FUTURE ROLE OF LONG TERM DOMICILIARY NIV}

There are now three potential roles for long term domiciliary NIV in patients with severe COPD. Firstly, patients who are genuinely intolerant of LTOT because of severe symptomatic hypercapnia may benefit from NIV if hypercapnia is controlled. Secondly, NIV may improve survival and quality of life in patients already established on LTOT but who are also hypercapnic. The published evidence to date does not support this role, but the existing randomised controlled trials can be criticised. A multicentre German study which aims to randomise a total of 300 patients to NIV or standard medical treatment with all cause mortality as the primary end point may help to answer this question. ${ }^{23}$ Thirdly, and perhaps most promisingly, NIV may have a role in patients who have required it because of a severe exacerbation. As detailed above, these are patients with a poor prognosis and the study by $\mathrm{Chu}$ et al ${ }^{13}$ provides useful further data to inform the power calculation of a prospective randomised controlled trial with the important end points of survival and hospitalisation rates. The drop out rate from the NIV group should be low as patients randomised to the intervention will have had personal experience already; those who do not like it or cannot tolerate it are likely to refuse home ventilation and therefore randomisation to the study. Patients may not need to use NIV during sleep ${ }^{24}$ or every day $^{25}$ to gain benefit. Diaz et $a l^{25}$ in a physiological study of 36 patients comparing NIV with sham ventilation delivered during wakefulness for 3 hours per day 5 days per week over a period of 3 weeks showed impressive changes in diurnal arterial blood gas tensions. This study suggests that even short periods of NIV during the day may have an effect in patients with ventilatory failure due to COPD.

The stage is now set for a randomised controlled trial comparing domiciliary NIV with conventional treatment in patients who have been ventilated non-invasively during an acute exacerbation. As well as survival, quality of life and a detailed health economic analysis are needed. Patients should be encouraged to use the ventilator each night during sleep but, if they are unable to do this, daytime use may still be beneficial. Even those whose use is only intermittent may still derive benefit, both in terms of daytime function ${ }^{25}$ and also by reducing the impact of the excacerbation. If benefit is confirmed, monitoring the pattern of use-which is now easy with microprocessor technology-will provide important insights into how this intervention might help patients.

Thorax 2004;59:1006-1008.

doi: $10.1136 /$ thx.2004.028027

Correspondence to: $\operatorname{Dr} M$ W Elliott, Consultant Respiratory Physician, St James's University Hospital, Beckett Street, Leeds LS9 7TF, UK; mwelliott@doctors.org.uk

Conflict of interest: The author has been loaned equipment by ventilator manufacturers for use in research studies and has received consultancy fees.

\section{REFERENCES}

1 Peter JV, Moran JL, Phillips-Hughes J, et al Noninvasive ventilation in acute respiratory failure: a meta-analysis update. Crit Care Med 2002;30:555-62.

2 Lightowler JV, Wedzicha JA, Elliott MW, et al. Non-invasive positive pressure ventilation to treat respiratory failure resulting from exacerbations of chronic obstructive pulmonary disease: Cochrane systematic review and meta-analysis. $B M$ 2003:326:185-9.

3 Connors AF Jr, Dawson NV, Thomas C, et al. Outcomes following acute exacerbation of severe chronic obstructive lung disease. The SUPPORT investigators (Study to Understand Prognoses and Preferences for Outcomes and Risks of Treatments). Am J Respir Crit Care Med 1996;154:959-67.

4 British Thoracic Society Standards of Care Committee. Non-invasive ventilation in acute respiratory failure. Thorax 2002:57:192-211.

5 Conti G, Antonelli $M$, Navalesi $P$, et al. Noninvasive vs. conventional mechanical ventilation in patients with chronic obstructive pulmonary disease after failure of medical treatment in the ward: a randomized trial. Intensive Care Med 2002;28:1701-7.

6 Confalonieri M, Parigi P, Scartabellati A, et al. Noninvasive mechanical ventilation improves the 
immediate and long-term outcome of COPD patients with acute respiratory failure. Eur Respir J 1996:9:422-30.

7 Vitacca M, Clini E, Rubini F, et al. Non-invasive mechanical ventilation in severe chronic obstructive lung disease and acute respiratory failure: short- and long-term prognosis. Intensive Care Med 1996;22:94-100.

8 Shneerson JM. The changing role of mechanical ventilation in COPD. Eur Respir J 1996;9:393-8.

9 Coakley JH, Nagendran K, Ormerod IE, et al. Prolonged neurogenic weakness in patients requiring mechanical ventilation for acute airflow limitation. Chest 1992;101:1413-6.

10 Berek K, Margreiter J, Willeit J, et al. Polyneuropathies in critically ill patients: a prospective evaluation. Intensive Care Med 1996;22:849-55.

11 Plant PK, Owen JL, Elliott MW. Non-invasive ventilation in acute exacerbations of chronic obstructive pulmonary disease: long term survival and predictors of in-hospital outcome. Thorax 2001;56:708-12.

12 Scala R, Bartolucci S, Naldi M, et al. Comorbidity and acute decompensations of COPD requiring non-invasive positive-pressure ventilation. Intensive Care Med 2004;30: 1747-54.

13 Chu CM, Chan VL, Lin AWN, et al. Readmission rates and life threatening events in COPD survivors treated with non-invasive ventilation for acute hypercapnic respiratory failure. Thorax 2004;59:1020-5.

14 Casanova C, Celli BR, Tost L, et al. Long-term controlled trial of nocturnal nasal positive pressure ventilation in patients with severe COPD. Chest 2000;118:1582-90.

15 Clini E, Sturani C, Rossi A, et al. The Italian multicentre study on noninvasive ventilation in chronic obstructive pulmonary disease patients. Eur Respir J 2002;20:529-38.

16 Elliott MW. Noninvasive ventilation in chronic ventilatory failure due to chronic obstructive pulmonary disease. Eur Respir J 2002;20:51 1-4.

17 Appendini L, Patessio A, Zanaboni S, et al. Physiologic effects of positive end-expiratory pressure and mask pressure support during exacerbations of chronic obstructive pulmonary disease. Am J Respir Crit Care Med 1994; 149:1069-76.

18 Bott J, Carroll MP, Conway JH, et al. Randomised controlled trial of nasal ventilation in acute ventilatory failure due to chronic obstructive airways disease. Lancet 1993;341:1555-7.

19 Plant PK, Owen JL, Elliott MW. Early use of non-invasive ventilation for acute exacerbations of chronic obstructive pulmonary disease on general respiratory wards: a multicentre

\section{Detecting early lung disease in cystic fibrosis: are current techniques sufficient?}

\section{P D Sly, S Brennan}

\section{Use of the multiple breath inert gas washout technique in the early diagnosis of $\mathrm{CF}$}

$\mathrm{T}$ he philosophy underlying treatment at most cystic fibrosis (CF) clinics is essentially preventative-that is, early detection, treatment and hopefully resolutions of problems before they become major clinical issues. The introduction of newborn screening programmes around the world is also based on the idea that early detection and treatment will result in an improved outcome for patients. Progressive lung disease represents the greatest threat to the health and well being of patients with CF. The goal of treatment is to prevent or delay progressive lung disease, so early detection and monitoring of effective treatments would be expected to improve the health and life expectancy of children with CF.

Lung disease in CF is characterised by a progression from bacterial colonisation to mucosal infection and finally invasive infection. This is accompanied by a host inflammatory response characterised by cytokine secretion and influx of neutrophils. The neutrophils appear to be drawn to the lungs largely by a chemotactic protein, interleukin 8 (IL-8), that is found in increased levels in the sputum and lavage of patients with CF. ${ }^{12}$ Increased numbers of neutrophils result in increased levels of the products of activated neutrophils such as neutrophil elastase (NE). Unbound $\mathrm{NE}$ is thought to be responsible for much of the lung damage seen in CF. Breakdown products of elastin found in the urine of patients with CF are thought to originate in the lung, indicating that lung destruction is occurring.

Recent studies provide strong evidence that lung disease begins during early life in most children with CF. Bronchoalveolar lavage (BAL) performed in infants and young children with CF shows evidence of inflammation and infection early in life, even in children who are asymptomatic at the time. ${ }^{45}$ A significant proportion of children diagnosed by newborn screening have been shown to have inflammation randomised controlled trial. Lancet 2000;355: 1931-5.

20 Tuggey JM, Plant PK, Elliott MW. Domiciliary non-invasive ventilation for recurrent acidotic exacerbations of COPD: an economic analysis Thorax 2003;58:867-71.

21 Jenkinson C, Davies RJ, Mullins R, et al. Comparison of therapeutic and subtherapeutic nasal continuous positive airway pressure for obstructive sleep apnoea: a randomised prospective parallel trial. Lancet 1999;353:2100-5.

22 Gay PC, Hubmayr RD, Stroetz RW. Efficacy of nocturnal nasal ventilation in stable, severe chronic obstructive pulmonary disease during a 3-month controlled trial. Mayo Clin Proc 1996;71:533-42.

23 Kohnlein T, Criee C-P, Kohler D, et al. Multicenter study on non-invasive ventilation in patients with severe chronic obstructive pulmonary disease and emphysema (COPD). Pneumologie 2004:58:566-9.

24 Schonhofer B, Geibel M, Sonnerborn M, et al. Daytime mechanical ventilation in chronic respiratory insufficiency. Eur Respir $J$ 1997; 10:2840-6.

25 Diaz O, Begin P, Torrealba B, et al. Effects of noninvasive ventilation on lung hyperinflation in stable hypercapnic COPD. Eur Respir J 2002;20:1490-8.

and infection, including Pseudomonas aeruginosa, before the onset of any respiratory symptoms. ${ }^{6}$ Armstrong et al also showed that much of this inflammation could be reduced by antibiotic treatment. ${ }^{1}$ These data demonstrate the usefulness of BAL for monitoring patients in the long term and for tailoring treatments to individual patients. However, BAL is invasive, requires general anaesthesia in young children, and cannot be repeated frequently. In addition, the presence of inflammation on BAL may not equate directly to progressive lung disease.

Lung imaging with high resolution computed tomography (HRCT) in children with CF shows that irreversible structural changes can occur long before reliable measurements of lung function can be obtained using conventional techniques at around school age. ${ }^{7}$ In older children changes on the HRCT scan are more sensitive than changes in pulmonary function. ${ }^{710}$ The use of HRCT in conjunction with lung function has been proposed as a sensitive marker of treatment outcomes. ${ }^{11}$ However to have an impact on preventing or delaying progressive lung disease, these assessments must be done before lung disease has become irreversible. No studies to date have investigated the relationships between structural changes (especially in the lower lobes) and inflammatory markers in the initiating stages of lung disease. Likewise, no data have been published investigating the relationships between early structural and physiological changes, despite the fact that abnormal lung function has been demonstrated in infants and preschool children. ${ }^{12-14}$ 
Lung function measured by standard spirometry in school age children with CF is insensitive to structural damage seen on HRCT scanning. Many children with clinically apparent lung disease (for example, daily cough with sputum production) have normal spirometric indices due to a lack of sensitivity of standard spirometric tests. Reliable measurements of lung function are now available for infants and preschool children. Careful measurements of pulmonary function in infants and young children with CF show detectable abnormalities early in the clinical course. ${ }^{12}{ }^{13}{ }^{15-17}$ Two recent studies have compared inflammatory indices with lung function measures taken concurrently. ${ }^{16}{ }^{17}$ Nixon et al demonstrated lower lung function-as measured by raised volume rapid thoracoabdominal compression-in those with clinically apparent lung disease. ${ }^{17}$ In this study lung function did not appear to be related to inflammation per se. In contrast, Dakin et al ${ }^{16}$ identified significant relationships between specific respiratory system compliance (sCRS), the pathogen load, and the number of neutrophils in the BAL fluid. None of the previous studies has used a technique that is capable of providing separate estimates of the mechanical properties of airway and pulmonary parenchyma. Lung disease in CF begins in the distal parts of the lung and should be reflected in abnormalities of parenchymal mechanics. The low frequency forced oscillation technique (LFOT) allows the measurement of the respiratory system impedance (Zrs) at a range of frequencies and enables lung function to be partitioned into components representing the airways and pulmonary parenchyma. However, no systematic studies aimed at detection of early lung disease in infants with CF using this technique have been published to date.

One of the relatively ignored areas of lung function testing has been that of ventilation distribution. An "old fashioned" test that is currently generating considerable interest is the multiple breath inert gas washout (MBW) technique. This can be used to measure lung volume and regional ventilation distribution and has been shown to correlate well with standard spirometric techniques in older children and adults. MBW has recently been applied to early detection of lung disease in CF with very promising preliminary results. ${ }^{18}$ When compared with standard spirometry in children old enough to make both measurements, a significantly higher number of children were identified as abnormal by multiple breath gas mixing technique $(72 \%)$ identified by standard spirometry $(23 \%) .{ }^{18}$
In this issue of Thorax Aurora et al ${ }^{19}$ report the results of MBW performed with sulfur hexafluoride $\left(\mathrm{SF}_{6}\right)$ in healthy school age British children and those with CF. The authors compared both volume $\left(\mathrm{FEV}_{1}\right)$ and flow $\left(\mathrm{MEF}_{25}\right)$ parameters obtained by standard spirometry with the lung clearance index (LCI) derived by MBW in 22 children with CF aged 6-16 years and 33 healthy controls. The LCI essentially measures the number of times the lungs need to be flushed out with air to remove the $\mathrm{SF}_{6}$. Poorly ventilated lung regions take longer to wash out, resulting in a prolongation of LCI. On group mean data, lung function-assessed either from spirometry or from MBW-was abnormal in the children with CF. LCI appeared to be a more sensitive index of lung disease in CF; while approximately half the children had normal spirometric results (as judged by a z-score of more than -1.96$)$, only one child had a normal LCI. These data are very similar to those published earlier by these authors in a Swedish population. ${ }^{18}$

There are several very encouraging implications from the data presented by Aurora et al. ${ }^{19}$ They show that LCI is repeatable with a very acceptable within-subject coefficient of variation for both CF $(6 \%)$ and healthy controls $(5 \%)$. They also show that the normal values for LCI are independent of age, at least for children over the age of 6 years. In addition, they show that the normal data obtained from British children are essentially identical to those obtained from healthy Swedish children, a finding that should encourage the rapid compilation of an international reference data set.

While the study by Aurora et $a l^{19}$ and the earlier study by these authors ${ }^{18}$ are very encouraging, neither really addresses the issue of whether MBW can be used to detect lung disease early enough in the course of CF to prevent the onset of lung destruction. Most of the children in both studies had abnormal lung function and presumably already had lung destruction. Little of the work to date with MBW in CF has been done in infants and preschool children, and no systematic examination has been undertaken comparing MBW with markers of inflammation, HRCT or measurements of peripheral lung mechanics. A series of systematic studies in younger children will be required to understand whether any of our current tests have the ability to detect the onset of lung destruction, whether they are suitable as outcome variables for new treatments aimed specifically at preventing lung damage, and whether they will be useful for predicting the long term outcome. MBW is a technique that is potentially useful from infancy to adulthood, even in the difficult preschool years. Time will tell whether MBW-used either alone or in combination with other tests-will be the answer.

Thorax 2004;59:1008-1010.

doi: 10.1136/thx.2004.025924

\section{Authors' affiliations}

P D Sly, S Brennan, TVW Telethon Institute for Child Health Research, Subiaco, Western Australia 6008, Australia

Correspondence to: Professor P D Sly, TVW Telethon Institute for Child Health Research, Subiaco, Western Australia 6008, Australia; peters@ichr.uwa.edu.au

\section{REFERENCES}

1 Armstrong D, Grimwood K, Carlin JB, et al Lower airway inflammation in infants and young children with cystic fibrosis. Am J Respir Crit Care Med 1997:156:1197-204.

2 Muhlebach MS, Stewart PW, Leigh MW, et al. Quantitation of inflammatory responses to bacteria in young cystic fibrosis and control patients. Am J Respir Crit Care Med 1999; 160:186-91.

3 Stone PJ, Konstan MW, Berger M, et al. Elastin and collagen degradation products in urine of patients with cystic fibrosis. Am J Respir Crit Care Med 1995;152:157-62.

4 Armstrong D, Grimwood K, Carzino R, et al. Lower respiratory infection and inflammation in infants with newly diagnosed cystic fibrosis. BMJ 1995:310:1571-2

5 Khan TZ, Wagener JS, Bost T, et al. Early pulmonary inflammation in infants with cystic fibrosis. Am J Respir Crit Care Med 1995; 151:1075-82.

6 Brennan S, Turner SW, Pitrez PMC, et al. Comparison of inflammatory profiles from the bronchoalveolar lavage fluid of infants identified by either newborn screening or clinical presentation under two years of age. Pediatr Pulmonol 2002; S24:318.

7 Tiddens HA. Detecting early structural lung damage in cystic fibrosis. Pediatr Pulmonol 2002;34:228-31.

8 Marchant JM, Masel JP, Dickinson FL, et al. Application of chest high-resolution computed tomography in young children with cystic fibrosis. Pediatr Pulmonol 2001;31:24-9.

9 Dakin CJ, Pereira JK, Henry RL, et al. Relationship between sputum inflammatory markers, lung function, and lung pathology on high-resolution computed tomography in children with cystic fibrosis. Pediatr Pulmonol 2002;33:475-82.

10 Demirkazik FB, Ariyurek OM, Ozcelik U, et al. High resolution $\mathrm{CT}$ in children with cystic fibrosis: correlation with pulmonary functions and radiographic scores. Eur J Radiol 2001;37:54-9.

11 Robinson TE, Leung AN, Northway WH, et al. Composite spirometric-computed tomography outcome measure in early cystic fibrosis lung disease. Am J Respir Crit Care Med 2003;168:588-93.

12 Turner DJ, Lanteri CJ, LeSouef PN, et al. Improved detection of abnormal respiratory function using forced expiration from raised lung volume in infants with cystic fibrosis. Eur Respir J 1994;7:1995-9

13 Ranganathan SC, Bush A, Dezateux C, et al Relative ability of full and partial forced expiratory maneuvers to identify diminished airway function in infants with cystic fibrosis. Am J Respir Crit Care Med 2002;166:1350-7.

14 Davis S, Jones M, Kisling J, et al. Comparison of normal infants and infants with cystic fibrosis using forced expiratory flows breathing air and heliox. Pediatr Pulmonol 2001;31:17-23. 
15 Gappa M, Ranganathan SC, Stocks J. Lung function testing in infants with cystic fibrosis: lessons from the past and future directions. Pediatr Pulmonol 2001;32:228-45.

16 Dakin CJ, Numa AH, Wang $H$, et al. Inflammation, infection, and pulmonary function in infants and young children with cystic fibrosis. Am J Respir Crit Care Med 2002; 165:904-10.

17 Nixon GM, Armstrong DS, Carzino R, et al. Early airway infection, inflammation, and lung function in cystic fibrosis. Arch Dis Child 2002;87:306-11.

18 Gustafsson $\mathrm{P}$, Aurora $\mathrm{P}$, Lindbland A. Evaluation of ventilation maldistribution as an early indicator of lung disease in children with cystic fibrosis. Eur Respir J 2003;22:972-9.

19 Aurora P, Gustafsson P, Bush A, et al. Multiple breath inert gas washout as a measure of ventilation distribution in children with cystic fibrosis. Thorax 2004;59 1068-73.
Funding of grant applications

\section{Getting grant applications funded: lessons from the past and advice for the future}

\section{G J Laurent}

\section{Respiratory research deserves more funding. This editorial proposes ways this can be achieved}

$\mathrm{T}$ hroughout the world respiratory research is underfunded with a large discrepancy between the proportion of patients suffering from lung diseases and the amount of research funds awarded by our national agencies. $^{1-4}$ In fact, many governmentsincluding the current British government-acknowledge this and are committed to directing more resources into an area where the diseases often affect the most vulnerable in our society. In this editorial I have attempted to analyse how we have got into this "Cinderella" state, and try to propose practical approaches to help us get more funding into respiratory research. The discussion focuses on Britain, but it is hoped that some of the suggestions might resonate with respiratory colleagues in other countries where similar underfunding is in danger of undermining valuable clinical strengths that have been nurtured over many years.

This article predominantly assesses the state of affairs in the more basic science, but it is hoped that it will also promote debate around more clinical and translational research which is so central to progress in patient care. In this area it is my sense that the respiratory community still has a strong reputation. However, whereas in the past these studies were predominantly supported by government agencies, the recent trend is for more and more dependency on pharmaceutical companies. This may be inevitable-and even desirable-as we seek new drugs and refine old ones, but at the very least the trend requires analysis.

\section{WHY IS RESPIRATORY RESEARCH} CURRENTLY UNDERFUNDED?

There has, for as long as I can remember, been a feeling that respiratory research is poorly funded compared with other disciplines where patient numbers are comparable. This feeling is also borne out by the numbers provided by the major funding bodies such as the Wellcome Trust and the Medical Research Council. For example, while deaths from respiratory disease accounted for $13 \%$ of all deaths in England and Wales in 2002, funding for respiratory research claimed only $2.8 \%$ ( $£ 11.4$ million) of the MRC's total expenditure in 2001-2 (£412.9 million). ${ }^{5-7}$ Why should this be the case? When you challenge the leaders of the funding bodies their response is almost always that "we need to look at ourselves, not them". They point out that all their grants are peer reviewed in the same way and that, if grants in respiratory medicine were as highly rated as grants in other areas, they would also get funded. Let's accept this for a moment and try to analyse why. One possible answer lies in history. In the late 1970s, in Britain at least, respiratory research was confined to a few centres and was largely of the "measure and correlate it" type, with the main aim to monitor response to treatment rather than elucidate mechanisms of disease. At this time, research in other areas (cardiology, neuroscience and oncology, for example) was already embracing the new opportunities provided by progress in cell and molecular biology. This yielded strong progress that laid the foundations to establish many centres throughout Britain where the next generation of people are now benefiting The respiratory world needed to catch up and, to a great extent, it has now done so.

My sense is that this discrepancy between respiratory medicine and other disciplines applies to most countries, although the time scales are different. In the US, for example, there was a concerted move to embrace molecular biology at least a decade before this occurred in Europe. However, even in the US it could be argued that we let our colleagues in other areas of medical research get the jump on us, and this may partly explain why the impact factors of specialist journals in many other areas are often higher than those in respiratory medicine.

The last 25 years has seen unprecedented growth in basic respiratory research, particularly in key centres. This growth explains the current status of the many groups who are now recognised as world leaders in medical research. Nevertheless, not all of these centres are well supported by the established funding bodies. One possible reason for this is that we are, despite progress, still not writing grant applications of the highest calibre. I will return to this later. Another possibility is that the peer review process in the respiratory world is leading to lower rating not based purely on the quality of the science. In other words, as a community we set the bar higher than our colleagues in other medical disciplines and look for reasons not to fund. This is hard to assess objectively but it is certainly my sense that, in Britain at least, we are a very critical community. For example, there is no doubt that in some areas such as asthma research we are worldwide leaders by any standards, but this may work against us as competing asthma researchers sense (often incorrectly) that there is a limited cake to be portioned among their peers.

\section{THE WAY FORWARD}

\section{Lobby the funding agencies}

All of us leading research need to coordinate with each other and provide a strong lobby for government support, both at national and international 
levels. Combating lung disease is central to our government's goals as outlined in the "Health of the Nation" document published in the first term of the current Labour government. We need to lobby for support and seek special initiatives to target the areas of respiratory medicine in which research is urgently needed to match our community expectations.

\section{Continue to attract the best scientists and physicians into respiratory research}

It is my sense that we have not always got the top of the crop into respiratory research, from the pools of both medical and science graduates. Furthermore, this is a vicious circle-if we don't have the funding we can't attract the best people who will in turn attract the best grants to allow them to flourish. We need to be more proactive in providing incentives and good career structures for our young talent. Furthermore, once we get people into respiratory medicine we must mentor them carefully. They need to be advised on how vital it is to obtain degrees of the highest quality and to perform their studies in the best laboratories worldwide. With this grounding, they will be in a position to compete with the very best graduates across the disciplines and obtain appropriate funding to fuel their desire to make important discoveries.

The long term career structures in academic medicine also need to improve along with financial incentives at least comparable to those in full time clinical practice. Equally, we must give scientists working in respiratory medicine an opportunity to rise to the very top of our medical schools and direct their own departments and research centres. Of course these are big issues, but the senior people in respiratory medicine must continue to make the case to their deans, vice-chancellors, provosts, and NHS chiefs.

\section{Write better grant applications, recognising the need to take a multidisciplinary approach}

We can all work on improving our grant applications. Rightly or wrongly funding is, to some extent, blind to the past. Track record is still very important but, if you do not write a grant with the key elements of novelty, focus, clear hypothesis and testable aims, you are probably sunk. Furthermore, if you avoid the trend to take a multidisciplinary approach, attacking a problem with all the tools available, you are also likely to fail. If this cannot be done within the confines of your own centre, then look for collaborators outside. One piece of practical advice: write your grant applications early and then take counsel from colleagues on how to improve them. Good grants need time to gestate.

\section{Be better referees}

All of us has a duty to the funding bodies to provide objective and impartial reviews. If we do not believe we can do this, we should return the grant applications and say so. We should also, when we review our peers, begin with the strengths rather than immediately attack weaknesses (which are inevitably present). We should first highlight the importance of the research area. Are there any areas of respiratory research (from the common airway diseases through to the orphan diseases) that are not worthy of support? Say So. Secondly, begin with the strengths. Many of our centres are led by extremely talented individuals who often have first rate international reputations. These strengths should be stated. In many cases we also have state of the art science faculties linked to unique clinical resources. These strengths should also be acknowledged. Simply stating a list of criticisms of experimental detail is, on its own, not appropriate. Of course, if there are fatal flaws in experimental design then this should be stated and the grant application should, quite rightly, fail.

Our grants committees usually recognise that a balanced judgement based on input from multiple referees is essential for fair grant assessment. This by and large works well but, in Europe at least, respiratory grant applications are often assessed by multidisciplinary panels representing all areas of medical research. It is therefore vital that we have good representation on these committees and we must be proactive in ensuring this. In the US, where respiratory funding is usually decided by individuals who are themselves involved in respiratory research, this is much less of a problem. Perhaps this is a better model for other governments and funding bodies to consider.

\section{CONCLUSIONS}

The last 25 years have seen huge strides in basic lung research and we have reason to be optimistic about the future. The products of this research are beginning to be realised. ' We also await translation of others through to clinical practice and, in this sense, it is vital that researchers in all areas of respiratory medicine work together to optimise the fruits of their outputs. ${ }^{10}$ In Britain and elsewhere we have many established centres and new ones are arising around the dispersed talents. The existence of strong basic science programmes supported by strong clinical research should engender confidence in physicians and scientists considering entering respiratory research and seeking funding for their work. However, at times I hear colleagues express a sense of nihilism regarding funding, partly arising from the observations that some of the very best groups are inadequately funded from these sources. We must work at eliminating this. Let's continue to attract top young scientists and physicians into respiratory research. Let's lobby our governments in a coordinated and constructive way, as is currently seen in the US. Finally, let's continue to be positive, submitting the very best grants we can and being balanced referees for our talented peers.

Thorax 2004;59:1010-1011.

doi: $10.1136 /$ thx.2004.024182

Correspondence to: Professor G J Laurent, Director, Centre for Respiratory Research, Department of Medicine, Rayne Institute, University College London, London WCíE 6JJ, UK; g.laurent@ucl.ac.uk

\section{REFERENCES}

1 Chung F, Barnes N, Allen M, et al. Assessing the burden of respiratory disease in the UK. Respir Med 2002;96:963-75.

2 Loddenkemper R, Gibson GJ, Sibille Y. The burden of lung disease in Europe: why a European White Book on lung disease? Eur Respir J 2003;22:869.

3 Whyte M. The role of research. In: British Lung Foundation Lung Report III: Casting a shadow over the nation's health 2003:43-4.

4 Spiro S. Lung cancer. In: British Lung Foundation Lung Report III: Casting a shadow over the nation's health 2003:16-8.

5 Office of National Statistics. Causes of death in 2002. London: National Statistics, 2003.

6 Medical Research Council. Leading science for better health: asthma and other respiratory disorders 2004, http://www.mrc.ac.uk/txt/ index/current-research/current-overview/ current-13_research_divisions/currentasthma_and_other_respiratory_disorders.htm.

7 Tobin MJ. Impact factor and the journal. Am J Respir Crit Care Med 2003;168:621-2.

8 Medical Research Council. MRC annual report 2001-2002. London: Medical Research Council, 2000

9 Lenfant C. Greater funding of cell and molecular biology has delivered what was promised to respiratory medicine. Am J Respir Crit Care Med 2004; 169:437-8.

10 Macklem PT. Is cell and molecular biology divorcing from clinical practice? Am J Respir Crit Care Med 2003;167:1164-5. 